\title{
Inhibition Effects of Pyrazine and Piperazine on the Corrosion of Mg-10Gd-3Y-0.5Zr Alloy in an Ethylene Glycol Solution
}

\author{
Daobing Huang ${ }^{1,2}$, Yuanqiang Tu${ }^{1}$, Guangling Song ${ }^{3}$, Xingpeng Guo ${ }^{2}$ \\ ${ }^{1} \mathrm{R} \& \mathrm{D}$ Center of Wuhan Iron and Steel Co., Wuhan, China \\ ${ }^{2}$ School of Chemistry and Chemical Engineering, Huazhong University of Science and Technology, \\ Hubei Key Laboratory of Materials Chemistry and Service Failure, Wuhan, China \\ ${ }^{3}$ Materials Science and Technology Division, Oak Ridge National Laboratory, Oak Ridge, USA \\ Email: huang_daobing@163.com, tyqiangbgs@wisco.com.cn, guangling.song@gmail.com, guoxp@mail.hust.edu.cn
}

Received March 4, 2013; revised April 4, 2013; accepted May 4, 2013

Copyright (C) 2013 Daobing Huang et al. This is an open access article distributed under the Creative Commons Attribution License, which permits unrestricted use, distribution, and reproduction in any medium, provided the original work is properly cited.

\begin{abstract}
The corrosion and inhibition effect of magnesium-based rare-earth containing alloy Mg-10Gd-3Y-0.5Zr (GW103) was studied in an ethylene glycol (EG) solution mixed with organic inhibitors. The inhibition efficiencies of piperazine and pyrazine inhibitors on the corrosion of GW103 were compared by means of potentiodynamic polarization curve, electrochemical impedance spectroscopy (EIS) and weight loss measurements. It was found that the corrosion process of GW103 alloy in EG solution was hindered by these two inhibitors and the inhibition of pyrazine was more effective than that of piperazine. It was implied that pyrazine could be an effective inhibitor for GW103 in an ethylene glycol coolant solution.
\end{abstract}

Keywords: GW103; Coolant; Inhibitor; Corrosion

\section{Introduction}

Magnesium alloys as structural materials is now being seriously considered in the auto industry due to their high strength/weight ratios which are critical to aircrafts and vehicles [1]. For example, the rare-earth containing MgGd-Y Mg alloys have higher specific strength and better creep resistance than conventional $\mathrm{Al}$ and $\mathrm{Mg}$ alloys [2, $3]$, and thus are being considered as engine block material candidates in the industry. It is well known that poor corrosion performance is now limiting the use of magnesium alloys as structural materials. Particularly, in an engine cooling system, corrosion is always a major concern. There is very limited information published on the corrosivity of ethylene glycol, the major constituent of a coolant, and the magnesium. Many commercially available coolants cannot give adequate corrosion protection to magnesium components [4]. Nevertheless, recently we find [5] that many organic chemicals can have an inhibition effect on Mg-10Gd-3Y-0.5Zr (GW103), a promising engine block Mg alloy. Encouraged by these promising findings, in this study we continue the search for more suitable organic inhibitors for the $\mathrm{Mg}$ alloy in the ethylene glycol solution.

\section{Experimental}

\subsection{Sample and Solution Preparation}

The material used in this study was Mg-10Gd-3Y-0.5Zr (GW103) magnesium alloy. Its chemical composition (wt. $\%$ ) is $10.32 \mathrm{Gd}, 3.60 \mathrm{Y}, 0.59 \mathrm{Zr}, 0.01 \mathrm{Mn}, 0.005 \mathrm{Ca}$, $<0.005 \mathrm{Al},<0.02 \mathrm{Cu},<0.005 \mathrm{Ni},<0.005 \mathrm{Fe}$ and balance $\mathrm{Mg}$. The alloy was machined into cylinder, welded to an electrical wire and mounted in Teflon leaving a $1.0 \mathrm{~cm}^{2}$ as working surface. Analytical grade chemicals were used. Ethylene glycol (EG), a mixture 50\% (vol\%) of EG and deionized water, was used as a blank EG solution. A small amount of the inhibitor was dissolved in deionized water or in ethanol if insoluble in water, then mixed with the blank EG solution.

\subsection{Electrochemical Measurements}

A conventional three-electrode cell was used with the GW103 as working electrode, Pt as auxiliary electrode and a saturated calomel electrode as reference electrode. Polarization curve and electrochemical impedance spectroscopy (EIS) were performed at $25^{\circ} \mathrm{C} \pm 1{ }^{\circ} \mathrm{C}$. The EIS 
measurement was performed with $10 \mathrm{mV}$ sinusoidal perturbations in the frequency range from $65 \mathrm{kHz}$ to $0.05 \mathrm{~Hz}$. The polarization curve was scanned from $-500 \mathrm{mV}$ to $600 \mathrm{mV}$ vs. the open circuit potential at $1 \mathrm{mVs}^{-1}$.

\subsection{Immersion Test}

The alloy was cut into $50 \mathrm{~mm} \times 10 \mathrm{~mm} \times 2 \mathrm{~mm}$ coupons for immersion test. Polished, cleaned and dried coupons were weighted for their original weights $\left(\mathrm{w}_{0}\right)$. They were immersed in the blank EG solution and the inhibitor containing solution as prepared in Section 2.1 for a certain period of time. After immersion, the corroded specimens were removed from the solutions, cleaned with demineralized water and dried, then immersed in a chromate (200 $\mathrm{g} / \mathrm{L} \mathrm{CrO}_{3}+10 \mathrm{~g} / \mathrm{L} \mathrm{AgNO}_{3}$ ) solution for 5 - $10 \mathrm{~min}$ to remove the corrosion products. Finally, the specimens were washed with demineralized water, dried and weighted again to obtain their final weights $\left(\mathrm{w}_{1}\right)$. The weight loss caused by corrosion was then calculated $\left(\mathrm{w}_{0}-\mathrm{w}_{1}\right)$. The weight loss measurements were repeated at least three times and the final average results are presented in this paper.

\section{Results and Discussion}

\subsection{Inhibition Effect of Organic Piperazine and Pyrazine}

The Nyquist plot of EIS of GW103 alloy in ethylene glycol mixed with $500 \mathrm{ppm}$ of piperazine and pyrazine at $25^{\circ} \mathrm{C}$ are presented in Figure 1. The Nyquist spectra show two characteristic capacitive loops at the high and low frequency ranges, respectively. The higher frequency capacitive loop could be assigned to the capacitance and resistance of the film on the alloy surface, while low frequency capacitive loop should be related to the corrosion process of the substrate $\mathrm{Mg}$ alloy exposed to the solution in the film pores. A conventional two-time equivalent circuit can be used to analyze the measured EIS and the fitting results are listed in Table 1.

In this equivalent circuit, $\mathrm{R}_{\mathrm{s}}$ is solution resistance and $\mathrm{C}_{1}$ is the capacitance of surface film; $\mathrm{R}_{1}$ is the surface film resistance. The constant phase element CPE1 is introduced to characterize the capacitance of the double layer. $R_{2}$ is the resistance of the substrate/film interface. The curve-fitting results quantitatively support the observations made in Figure 1.

The polarization curves of GW103 in ethylene glycol mixed with $500 \mathrm{ppm}$ of piperazine and pyrazine are presented in Figure 2 and the fitting results are listed in Table 2 .

It is shown that the addition of piperazine and pyrazine to the ethylene glycol solution improves the corrosion resistance of the magnesium alloy, which is in accordance with the results of the polarization curves. The in-

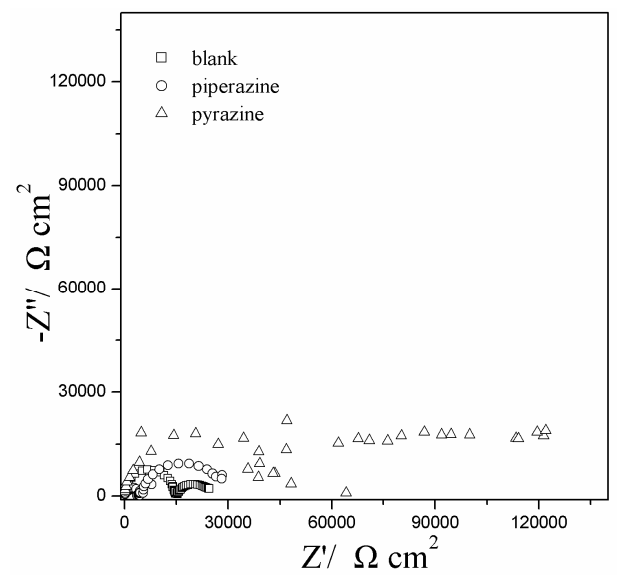

Figure 1. EISs of GW103 alloy in ethylene glycol solutions mixed with $500 \mathrm{ppm}$ of piperazine and pyrazine, respectively at $25^{\circ} \mathrm{C}$.

Table 1. EIS parameters of GW103 ethylene glycol solution mixed with $500 \mathrm{ppm}$ of piperazine and pyrazine, respectively at $25^{\circ} \mathrm{C}$.

\begin{tabular}{cccccc}
\hline \multirow{2}{25}{$\mathbf{C}$} & $\begin{array}{c}\mathbf{R}_{\mathbf{s}} \\
\left(\mathbf{\Omega} \mathbf{c m}^{2}\right)\end{array}$ & $\begin{array}{c}\mathbf{C}_{\mathbf{1}} \\
\left(\mathbf{F} / \mathbf{c m}^{\mathbf{2}}\right)\end{array}$ & $\begin{array}{c}\mathbf{R}_{\mathbf{1}} \\
\left(\mathbf{\Omega} \mathbf{c m}^{\mathbf{}}\right)\end{array}$ & $\begin{array}{c}\mathbf{C P E 1} \\
\left(\mathbf{F} / \mathbf{c m}^{2}\right)\end{array}$ & $\begin{array}{c}\mathbf{R}_{\mathbf{2}} \\
\left(\mathbf{\Omega} \mathbf{c m}^{2}\right)\end{array}$ \\
\hline Blank & 598.4 & $3.7 \mathrm{E}^{-9}$ & 14136 & $2.6 \mathrm{E}^{-5}$ & 10908 \\
Piperazine & 103.6 & $3.6 \mathrm{E}^{-9}$ & 4722 & $1.3 \mathrm{E}^{-5}$ & 23897 \\
Pyrazine & 228.8 & $2.2 \mathrm{E}^{-9}$ & 31750 & $5.1 \mathrm{E}^{-6}$ & 124390 \\
\hline
\end{tabular}

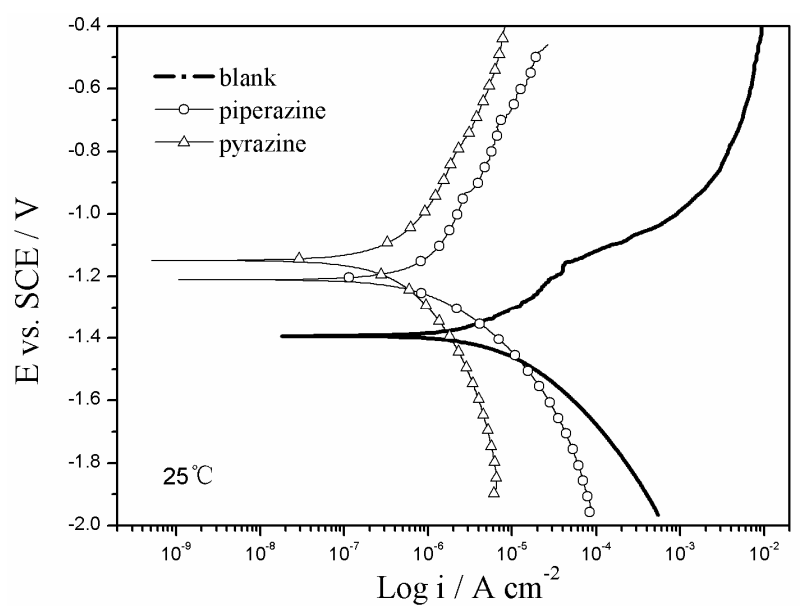

Figure 2. Polarization curves of GW103 alloy in ethylene glycol solutions mixed with $500 \mathrm{ppm}$ of piperazine and pyrazine, respectively at $25^{\circ} \mathrm{C}$.

Table 2. Polarization parameters of GW103 in ethylene glycol solutions mixed with $500 \mathrm{ppm}$ of piperazine and pyrazine, respectively at $25^{\circ} \mathrm{C}$.

\begin{tabular}{cccc}
\hline $25^{\circ} \mathrm{C}$ & $\mathrm{i}_{\text {corr }}\left(\mu \mathrm{A} \cdot \mathrm{cm}^{-2}\right)$ & $\beta_{\mathrm{c}}\left(\mathrm{mV} \cdot \mathrm{dec}^{-1}\right)$ & OCP $(\mathrm{mV})$ \\
\hline Blank & 27.9 & 371 & -1391 \\
Piperazine & 9.9 & 608 & -1212 \\
Pyrazine & 1.2 & 868 & -1149 \\
\hline
\end{tabular}


Table 3. Weight loss results of GW103 in EG solutions with different inhibitors after 3 days of immersion

\begin{tabular}{cccccccc}
\hline \multirow{2}{*}{ Concentration $(\mathrm{ppm})$} & \multicolumn{2}{c}{ Weight loss $(\mathrm{g})$} & \multicolumn{2}{c}{ Weight loss rate $\left(\mathrm{mg} / \mathrm{cm}^{2} \cdot \mathrm{week}\right)$} & \multicolumn{2}{c}{$\% \mathrm{IE}_{(\mathrm{w})}$} \\
\cline { 2 - 7 } & $25^{\circ} \mathrm{C}$ & $90^{\circ} \mathrm{C}$ & $25^{\circ} \mathrm{C}$ & $90^{\circ} \mathrm{C}$ & $25^{\circ} \mathrm{C}$ & $90^{\circ} \mathrm{C}$ \\
\hline Blank & 0.0045 & 0.0056 & 2.72 & 3.39 & - & - \\
500 ppm pyrazine & 0.0018 & 0.0016 & 1.09 & 0.97 & 65.9 & 76.9 \\
\hline
\end{tabular}

creased R2 values suggest a significant inhibition effect by the added inhibitors. Pyrazine has a better corrosion inhibition effect than piperazine.

\subsection{Weight Loss Measurements}

From the above discussion, pyrazine has a better inhibition effect than that of piperazine. Thus, the corrosion inhibition effect of the pyrazine is selected to conduct weight loss measurements. The weight loss measurement after 3 days immersion in EG solution with and without pyrazine at ambient and elevated temperatures is tested and the results are listed in Table 3. From the results we could see the weight loss measurement confirmed the electrochemical results.

From the above results, both piperazine and pyrazine could retard the corrosion of magnesium alloy and pyrazine has a better inhibition effect than piperazine. This might be due to the difference in the chemical structure: both piperazine and pyrazine contain $\mathrm{N}$ atoms with lonepair electrons which could be adsorbed on the magnesium alloy surface through $\mathrm{N}$ atoms. While, in addition, pyrazine contain three $\mathrm{C}=\mathrm{C}$ bonds with $\pi$-electrons which could provide electrons to unoccupied d-orbital of metal using antibonding orbit to form covalent bond. Therefore, pyrazine could be more easily than piperazine to be adsorbed on the magnesium alloy surface and thus showed a better inhibition effect.

\section{Conclusions}

1) Piperazine and pyrazine are strong inhibitors for GW013 Mg alloy in the EG solution. Pyrazine is relatively more inhibitive than piperazine which may be due to the difference in the chemical structure.

2) Pyrazine shows good inhibition effect on both ambient and elevated temperatures and may be an effective inhibitor for GW103 Mg alloy in ethylene glycol coolant.

\section{REFERENCES}

[1] X. Guo, J. Chang, S. He, et al., "Investigation of Corrosion Behaviors of Mg-6Gd-3Y-0.4Zr Alloy in NaCl Aqueous Solutions," Electrochimica Acta, Vol. 52, No. 7, 2007, pp. 2570-2577. doi:10.1016/j.electacta.2006.09.010

[2] S. M. He, X. Q. Zheng, L. M. Peng, et al., "Microstructure and Strengthening Mechanism of High Strength Mg-10Gd2Y-0.5Zr Alloy," Journal of Alloys and Compounds, Vol. 427, No. 1-2, 2007, pp. 316-323. doi:10.1016/j.jallcom.2006.03.015

[3] S. M. He, X. Q. Zheng, L. M. Peng, et al., "Microstructure Evolution in a Mg- $15 \mathrm{Gd}-0.5 \mathrm{Zr}$ Alloy during Isothermal Aging, "Journal of Alloys and Compounds, Vol. 421, No. 1-2, 2006, pp. 309-312. doi:10.1016/j.jallcom.2005.11.046

[4] G. Song and D. H. St. John, "Corrosion Behaviour of Magnesium in Ethylene Glycol," Corrosion Science, Vol. 46, No. 6, 2004, pp. 1381-1399. doi:10.1016/j.corsci.2003.10.008

[5] D. B. Huang, J. Y. Hu, G.-L. Song and X. P. Guo, "Inhibition Effect of Inorganic and Organic Inhibitors on the Corrosion of Mg-10Gd-3Y-0.5Zr Alloy in an Ethylene Glycol Solution at Ambient and Elevated Temperatures," Electrochimica Acta, Vol. 56, No. 27, 2011, pp. 1016610178. doi:10.1016/j.corsci.2003.10.008 